\title{
The post-annealing environment effect on the photoluminescence recovery of ion-irradiated Si nanocrystals
}

\author{
U.S. Sias $^{\mathrm{a}, \mathrm{b}, *}$, M. Behar ${ }^{\mathrm{a}}$, H. Boudinov ${ }^{\text {a }}$, E.C. Moreira ${ }^{\mathrm{c}}$ \\ ${ }^{a}$ Instituto de Física - Universidade Federal do Rio Grande do Sul (UFRGS), C. P. 15051, 91501-970 Porto Alegre, RS, Brazil \\ b Centro Federal de Educaçao Tecnológica de Pelotas (CEFET-RS), 96015-370 Pelotas, RS, Brazil \\ ${ }^{c}$ UFPel-UNIPAMPA, Campus Bagé, 96400-970 Bagé, RS, Brazil
}

\begin{abstract}
In the present work we have investigated the influence of the post-annealing environment on the photoluminescence (PL) recovery of Si nanocrystals after ion irradiation. Samples originally produced by $\mathrm{Si}$ implantation into $\mathrm{SiO}_{2}$ matrix at $600{ }^{\circ} \mathrm{C}$ post-annealed at $1100{ }^{\circ} \mathrm{C}$ were further bombarded with $2 \mathrm{MeV} \mathrm{Si}^{+}$, at a fluence of $\Phi=2 \times 10^{13} \mathrm{Si} / \mathrm{cm}^{2}$. After irradiation the original emission, composed by two PL bands, was completely quenched. We shown that the environment of a post-annealing performed at $900{ }^{\circ} \mathrm{C}$ has a strong effect on the PL emission recovery. The intensity and shape of the PL spectra have revealed to be dependent of the annealing gas ( $\mathrm{N}_{2}$ or $\mathrm{Ar}$ ), annealing time, as well as the original Si excess. The results are explained on the basis of current theories.
\end{abstract}

Keywords: Silicon nanocrystals; Photoluminescence; Hot implantation; Ion irradiation

\section{Introduction}

Si nanocrystals (NCs) embedded in a $\mathrm{SiO}_{2}$ matrix have been extensively studied as a function of the implantation fluence, annealing temperature and annealing time [1-4]. More recently, the influence of the annealing environment on the PL emission has been investigated and it has been demonstrated that the choice of the gas under which the annealing was performed had a strong influence on the PL peak intensity and position [5]. On the other hand, studies on the formation of defects in Si NCs have shown that after certain critical irradiation fluence the NCs PL emission is totally quenched [6]. However, a post-annealing at high temperature fully recovers the original PL. Such experiments on $\mathrm{Si}$ NCs were produced by room tempera-

\footnotetext{
- Corresponding author. Address: Instituto de Fisica - Universidade Federal do Rio Grande do Sul (UFRGS), C.P. 15051, 91501-970 Porto Alegre, RS, Brazil. Tel.: +55 51331665 51; fax: +55 5133166510 .

E-mail address: uilson@ocetetrs.tche.br (U.S. Sias).
}

ture (RT) ion implantation or PECVD techniques, followed by high annealing temperature (between 1000 and $1200^{\circ} \mathrm{C}$ ). In both cases, only a single PL emission band centered at around $800 \mathrm{~nm}[5,6]$ was observed. More recently, we have taken another experimental approach where the $\mathrm{Si}$ implantations into $\mathrm{SiO}_{2}$ matrix were performed keeping the substrate at high temperature (between 400 and $800^{\circ} \mathrm{C}$ ) [7]. By using a fluence of $1 \times 10^{17} \mathrm{Si} / \mathrm{cm}^{2}$ and post-annealing of $1100^{\circ} \mathrm{C}$, we have obtained a PL structure composed by two PL bands. One centered at $780 \mathrm{~nm}$ and another with higher intensity, centered at around $1000 \mathrm{~nm}$. Transmission electron microscopy observations (TEM) have revealed that the NCs size distribution was broader with larger nanoparticles, when compared with those obtained by RT Si implantations.

Based on the previous works [5-7] three questions can be raised. First, what would be the behavior of both PL bands after irradiation and further annealing at around $900{ }^{\circ} \mathrm{C}$ ? Second, should the above mentioned PL recovery be affected by the annealing atmosphere? Finally, how 


\section{U.S. Sias et al.}

important is the NCs size distribution in the PL recovery process?

In order to answer the above questions we have undertaken the present work. With this aim we have implanted $\mathrm{Si}$ into a $\mathrm{SiO}_{2}$ film keeping the substrate at $600{ }^{\circ} \mathrm{C}$, further annealed it at $1100^{\circ} \mathrm{C}$, forming the $\mathrm{Si} \mathrm{NCs}$ and inducing an intense PL emission. Further, we irradiated the $\mathrm{NCs}$ quenching their $\mathrm{PL}$ emission. In a sequence we annealed the samples at $900{ }^{\circ} \mathrm{C}$ under different annealing environments. In addition, we repeated the above mentioned procedure using different implantation fluences in order to investigate the influence of the NCs size distribution on the PL emission recovery. It should be pointed out that such samples, with two PL bands, are an interesting probe to investigate the Si NCs PL emission mechanisms.

\section{Experimental}

A $480 \mathrm{~nm}$-thick $\mathrm{SiO}_{2}$ layer thermally grown on a $\mathrm{Si}(100)$ wafer was implanted with $170 \mathrm{keV} \mathrm{Si}^{+}$ions at fluences of 1 and $3 \times 10^{17} \mathrm{Si} / \mathrm{cm}^{2}$ providing a peak concentration profile at around $240 \mathrm{~nm}$ depth with initial $\mathrm{Si}$ excess of about 10 and 30 at. $\%$, respectively. The samples were implanted at $600{ }^{\circ} \mathrm{C}$ and further annealed at $1100{ }^{\circ} \mathrm{C}$ under $\mathrm{N}_{2}$ atmosphere in a conventional furnace in order to nucleate and grow the $\mathrm{Si}$ precipitates. As a result, we have obtained samples with different Si NCs mean size and distribution profiles. Afterward, these samples were irradiated with a $2 \mathrm{MeV} \mathrm{Si}{ }^{+}$beam at a fluence of $2 \times 10^{13} \mathrm{Si} / \mathrm{cm}^{2}$. Under such conditions the original PL emission was completely quenched and the Si NCs were totally amorphized, as confirmed by the TEM observations (not shown here). In a next step, the as-irradiated samples were annealed at $900{ }^{\circ} \mathrm{C}$ in $\mathrm{N}_{2}$ or $\mathrm{Ar}$ atmospheres. As will be described below the PL emission was recovered, but with different characteristics, when compared to the original one.

PL measurements were performed at RT using a Xe lamp and a monochromator in order to get a wavelength of $488 \mathrm{~nm}(2.54 \mathrm{eV})$ as an excitation source. The resulting power density on the samples was of $20 \mathrm{~mW} / \mathrm{cm}^{2}$. The emission was dispersed by a $0.3 \mathrm{~m}$ single-grating spectrometer and acquired with visible-near infrared silicon and InGaAs cooled detectors. All spectra were obtained under the same conditions and corrected for the system response.

\section{Results}

\section{1. $\mathrm{N}_{2}$ annealing atmosphere}

In Fig. 1 we display the results for the fluence $\Phi=1 \times 10^{17} \mathrm{Si} / \mathrm{cm}^{2}$, where the PL spectrum corresponding to the as-implanted and $1100^{\circ} \mathrm{C}$ annealed sample is shown (full square). As can be observed in the Fig. 1(a), the PL distribution presents two bands, one centered at $780 \mathrm{~nm}$ and another around $1000 \mathrm{~nm}$. The Si irradiation performed at $2 \mathrm{MeV}$ quenched completely both PL bands. The subsequent annealing performed at $900{ }^{\circ} \mathrm{C}$ in $\mathrm{N}_{2}$ for $3.5 \mathrm{~h}$ brings as a consequence a full recovery of the original long wavelength PL band (open triangle). However, the same does not occur with the short wavelength region (below $800 \mathrm{~nm}$ ) as can be observed in Fig. 1(b), where is shown the relative PL intensity of irradiated samples normalized in relation to the original one. Further annealing for $7.5 \mathrm{~h}$ increases the PL intensity of the $1000 \mathrm{~nm}$ band by a factor of 2.5 , but still failed in reaching the original intensity at the short PL band (open circle). This is only achieved after $14.5 \mathrm{~h}$ of annealing time (open square). Under these conditions the intensity of the long wavelength
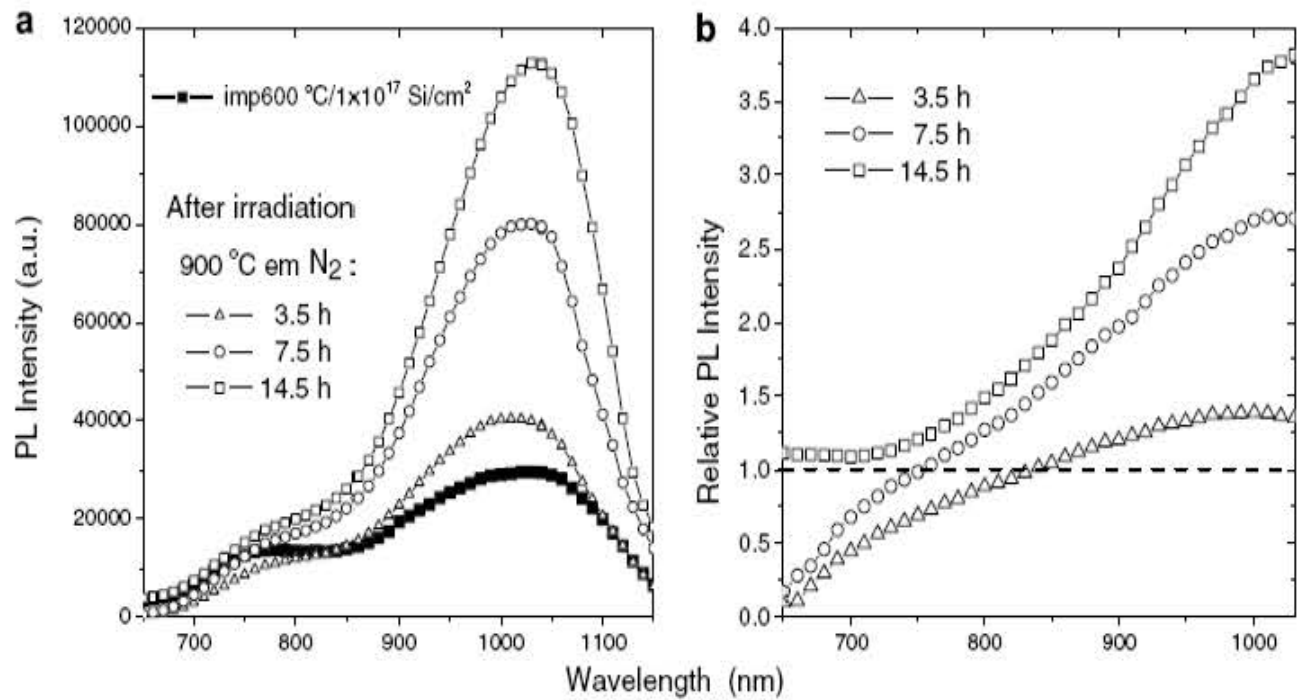

Fig. 1. (a) PL spectrum of the $1.0 \times 10^{17} \mathrm{Si} / \mathrm{cm}^{2}$ implanted sample annealed at $1100^{\circ} \mathrm{C}$ for $1 \mathrm{~h}$ ( and corresponding PL spectra after irradiation followed by $900{ }^{\circ} \mathrm{C}$ anneal in $\mathrm{N}_{2}$ atmosphere at different times; (b) relative PL intensity of normalized PL spectra after the $900^{\circ} \mathrm{C}$ anneal. Dashed line corresponds to the normalization relation to the original PL spectrum. 


\section{U.S. Sias et al}

PL band is almost four times higher than the emitted from the original sample - see Fig. 1, Further annealing times do not introduce any modification in the PL spectrum, indicating a saturation effect. By fitting both bands with Gaussian distributions (as described in [7]) we were able to observe that the peak positions of both PL bands did not suffer any shift, indicating that the $900{ }^{\circ} \mathrm{C}$ post-annealing did not introduce any modification in the original $\mathrm{Si} \mathrm{NCs}$ distribution. This feature was confirmed by TEM observations (not shown here), which shows that the mean size of the nanocrystals $(3 \mathrm{~nm})$ and its FWHM distribution $(1.6 \mathrm{~nm})$ remains the same as compared with the non-bombarded sample.

The Si implantation at $\Phi=3 \times 10^{17} \mathrm{Si} / \mathrm{cm}^{2}$ and further annealing at $1100{ }^{\circ} \mathrm{C}$ (not shown), presents two basic differences with the one performed at $1 \times 10^{17} \mathrm{Si} / \mathrm{cm}^{2}$. First, the $1000 \mathrm{~nm}$ band is relatively much higher than the $780 \mathrm{~nm}$ one (relation 40 to 1 as compared with 5 to 1 in the former case). Second, the $1000 \mathrm{~nm}$ band suffers a significant redshift of more than $70 \mathrm{~nm}$. The Si bombardment quenched both PL bands, but the $900{ }^{\circ} \mathrm{C}$ annealing for $3.5 \mathrm{~h}$ recovers both of them. However, at variance of what was described above and illustrated in Fig. 1, the long wavelength band shows a PL intensity that after $3.5 \mathrm{~h}$ of annealing is $20 \%$ higher than the original one, without changing the peak position. The same does not occur with the short wavelength band, where the original PL intensity is almost reached. Further annealing performed at 7.5 and $14.5 \mathrm{~h}$ brings as a consequence an increase of the PL intensity of both bands and saturation is reached again after $14.5 \mathrm{~h}$ of annealing time. It should be mentioned that after $7.5 \mathrm{~h}$ of annealing time the PL intensity of the $780 \mathrm{~nm}$ band became higher by almost $40 \%$ as compared with the non- bombarded sample. This is at variance with was observed for the sample implanted at $1 \times 10^{17} \mathrm{Si} / \mathrm{cm}^{2}$.

\subsection{Ar annealing atmosphere}

In Fig. 2 is shown the $\mathrm{PL}$ spectrum of the as-implanted at $\Phi=1 \times 10^{17} \mathrm{Si} / \mathrm{cm}^{2}$ and $1100^{\circ} \mathrm{C}$ annealed sample (full square). In the same figure are shown the corresponding PL spectra of the post-irradiated sample submitted at different annealing times at $900{ }^{\circ} \mathrm{C}$ in Ar. As illustrated in Fig. 2, 3.5 h of annealing time induces an almost full recovery of the long wavelength band, but felt well below the original level of the short wavelength band. The original PL intensity is obtained only for the long wavelength band after $5.5 \mathrm{~h}$ of annealing time (open star) and after $7.5 \mathrm{~h}$ of annealing (open circle) this band reaches the saturation regime. On the other hand, the original PL intensity of the $780 \mathrm{~nm}$ band was never achieved even for longer annealing times.

The situation slightly changes for the sample implanted at $3 \times 10^{17} \mathrm{Si} / \mathrm{cm}^{2}$ (not shown). After bombardment and further annealing for $3.5 \mathrm{~h}$ at $900^{\circ} \mathrm{C}$, the resulting $\mathrm{PL}$ intensity of the long wavelength band became around $30 \%$ higher than the original one with a significant redshift (around $70 \mathrm{~nm}$ ). A further annealing for $7.5 \mathrm{~h}$ induces a small PL intensity increase but longer annealing times did not produce any significant change. On the other hand, the short wavelength band never recovers its original intensity. In the present case, the ratio between the intensities of both bands after the $7.5 \mathrm{~h}$ of annealing was of order 40 as compared with the original sample where this relation was 10 times lower.

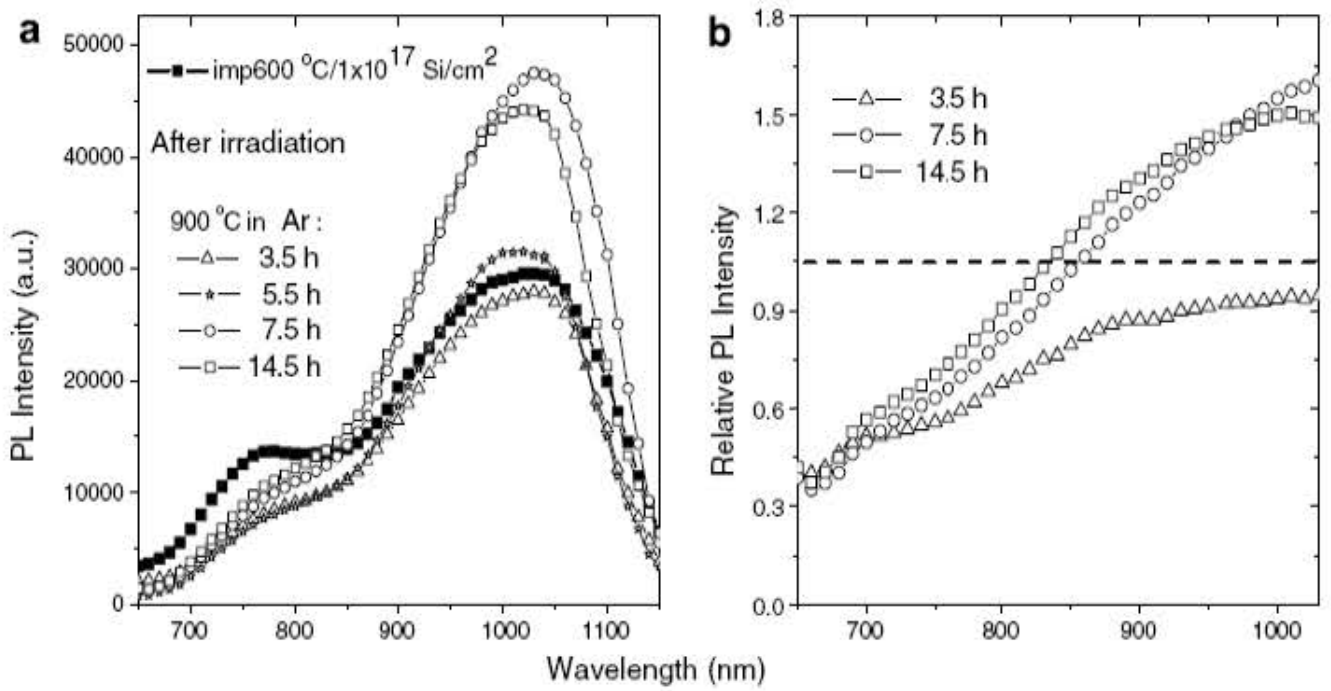

Fig. 2. (a) PL spectrum of the $1.0 \times 10^{17} \mathrm{Si} / \mathrm{cm}^{2}$ mplanted sample annealed at $1100{ }^{\circ} \mathrm{C}$ for $1 \mathrm{~h}(\mathbf{})$ and corresponding PL spectra after irradiation followed by $900^{\circ} \mathrm{C}$ anneal in Ar atmosphere at different times; (b) relative PL intensity of normalized PL spectra after the $900^{\circ} \mathrm{C}$ anneal. Dashed line corresponds to the normalization relation to the original PL spectrum. 


\section{U.S. Sias et al.}

\section{Discussion}

As was extensively discussed in the literature the luminescence emitted by $\mathrm{Si}$ NCs embedded in $\mathrm{SiO}_{2}$ has been either attributed to recombination via quantum confinement effects of carriers in the Si NCs nuclei or to recombination levels localized at the nanocrystal-matrix boundary.

Therefore, being clear the different behavior of the two PL bands observed in the present work, we will try to identify the nature of their PL emission.

As described in Section 3, we have done investigations with two different fluences, obtaining $\mathrm{Si}$ concentrations of 10 and 30 at. $\%$, respectively. As a consequence the Si NCs mean size was about 3 and $5 \mathrm{~nm}$, respectively. With increasing implantation fluence the PL band at around $1000 \mathrm{~nm}$ shows a significant redshift around $70 \mathrm{~nm}$. This behavior characterizes the $1000 \mathrm{~nm}$ band as having its origin to quantum confinement effects. In fact, it is predicted that with increasing $\mathrm{NCs}$ size the radiative transition decreases its energy and as a consequence increases its wavelength; feature that is observed in the present experiment.

On the other hand, despite the variation of the $\mathrm{Si} \mathrm{NCs}$ size produced in the present work, no shift has been observed for the band centered on $780 \mathrm{~nm}$. This behavior is characteristic of PL emission produced by radiative states at the $\mathrm{Si} / \mathrm{SiO}_{2}$ interface as recognized previously by other authors $[1,8-11]$. Therefore, we can conclude that both bands have basically different origins, one band on quantum size effects and the other on radiative interface states.

In what follows we are going to discuss the recovery of the $1000 \mathrm{~nm}$ band. As was demonstrated above the effect of the $900{ }^{\circ} \mathrm{C}$ thermal treatment after the irradiation process consists basically in annealing the damage inside and around the Si NCs already formed by the annealing at $1100{ }^{\circ} \mathrm{C}$. In facl, we have performed experiments where $1 \times 10^{17} \mathrm{Si} / \mathrm{cm}^{2}$ as-implanted samples were annealed at $900{ }^{\circ} \mathrm{C}$ and no PL signal was detected, as well as no NCs formation was observed by TEM analyses. On the other hand, it is known that anneal under $\mathrm{N}_{2}$ or $\mathrm{Ar}$ atmosphere induce a release in the interfacial stress at the $\mathrm{Si} / \mathrm{SiO}_{2}$ interface. Since stress is known to affect the concentration and morphology of defects at the $\mathrm{Si} / \mathrm{SiO}_{2}$ interface [12], any change in the level of stress should be expected to influence the PL intensity. Then, concerning the behavior of the $1000 \mathrm{~nm}$ PL band, we attributed that its variation of intensity after the $900^{\circ} \mathrm{C}$ anneal is (in addition to the Si NCs recrystallization due to stress relaxation at the $\mathrm{Si} / \mathrm{SiO}_{2}$ interface induced by the anneal atmosphere.

Considering the $1 \times 10^{17} \mathrm{Si} / \mathrm{cm}^{2}$ sample, the $\mathrm{N}_{2}$ or $\mathrm{Ar}$ environments produce qualitatively the same effects, but different quantitative results. In fact, we have to point out two major differences. First, under $\mathrm{N}_{2}$ annealing atmosphere the saturation regime is reached after longer annealing times ( 14.5 against $7.5 \mathrm{~h}$ for $\mathrm{Ar}$ ). Second, the saturation level of the PL intensity under $\mathrm{N}_{2}$ atmosphere is around twice the value obtained under Ar annealing one. The same features were observed for the highest implantation fluence.

The different behaviors described above can be explained using the following arguments. It is known that Ar is absolutely inert, then, an annealing under this atmosphere should induce a pure thermal relaxation. Therefore, it should only reduce the interfacial stress at the Si NCsmatrix interface and consequently, this effect should influence the PL emission.

On the other hand, although $\mathrm{N}_{2}$ is considered a relatively inert gas, it has been observed its reaction with $\mathrm{Si}$ at moderate temperatures $\left(760-1050^{\circ} \mathrm{C}\right)$ forming ultrathin oxinitride films [13]. Moreover, nitride passivation effects on the visible PL from Si NCs have been reported [14]. Therefore, as claimed in [5], the presence of nitrogen contributes not only to reduce the interfacial stress but also to passivate the interfacial bonds.

In summary, concerning the PL emission of the $1000 \mathrm{~nm}$ band we can state that the post-annealing after irradiation brings beneficial effects by increasing the PL intensity with increasing time. This is probably due to pure stress relaxation in the Ar case and to the same relaxation plus to a probably surface passivation effect induced by a thin oxinitride film in the $\mathrm{N}_{2}$ case, both in addition to the $\mathrm{Si}$ NCs recrystallization.

Regarding the $780 \mathrm{~nm}$ PL band, we have attributed its existence to radiative interfacial states. It is clear that $\mathrm{Ar}$ and $\mathrm{N}_{2}$ annealing not only recrystallize the $\mathrm{Si} \mathrm{NCs}$, but also rebuild in a not very efficient way the radiative states at the grain-matrix interface. This last feature is revealed by the poor recovery of the $\mathrm{PL}$ intensity as compared with the results obtained with the $1000 \mathrm{~nm}$ band.

In conclusion, we think that we were able to answer the questions that motivated the present work. First we have shown that the amount of PL recovery after the irradiation and further anneal is different for each band. It is much more pronounced for the band around $1000 \mathrm{~nm}$ than that at $780 \mathrm{~nm}$. Second, the $900^{\circ} \mathrm{C}$ annealing environment is more efficient under $\mathrm{N}_{2}$ than $\mathrm{Ar}$ atmosphere. Third, the NCs size distribution also has a very important role in the recovery process. The larger nanocrystals (long wavelength band emission) provide a PL intensity recovery that is much higher than the one induced by the small NCs. Finally, we were able to deduce that the PL band at $\sim 1000 \mathrm{~nm}$ has its origin to quantum confinement effects while the other has its origin at radiative interface states.

\section{Acknowledgment}

U.S. Sias thanks the Brazilian National Research Council $(\mathrm{CNPq})$ for financial support.

\section{References}

[1] T. Shimizu-Iwayama, D.E. Hole, I.W. Boyd, J. Phys.: Condens. Matter 11 (1999) 6595. 


\section{U.S. Sias et al}

[2] B. Garrido Fernandez, M. Lóppez, C. Garcíia, A. Pérez-Rodríguez, J.R. Morante, C. Bonafos, M. Carrada, A. Claverie, J. Appl. Phys. 9 (2002) 798 .

[3] S. Cheylan, R.G. Elliman, Appl. Phys. Lett. 78 (2001) 1912

[4] G.H. Li, K. Ding, Y. Chen, H.X. Han, Z.P. Wang, J. Appl. Phys. 88 (2000) 1439.

[5] A.R. Wilkinson, R.G. Elliman, J. Appl. Phys. 96 (2004) 4018.

[6] D. Pacifici, E.C. Moreira, G. Franzò, V. Martorino, F. Priolo, F Iacona, Phys. Rev. B 65 (2002) 144109.

[7] U.S. Sias, L. Amaral, M. Behar, H. Boudinov, E.C. Moreira, E. Ribeiro, J. Appl. Phys. 98 (2005) 34312.

[8] Y. Kanemitsu, T. Ogawa, K. Shiraishi, K. Takeda, Phys. Rev. B 48 (1993) 4883.
[9] X. Wu, A.M. Bittner, K. Kern, C. Eggs, S. Veprek, Appl. Phys. Lett. $77(2000) 645$.

[10] N. Pauc, V. Calvo, J. Eymery, F. Foumel, N. Magnea, Phys. Rev. B 72 (2005) 205325.

[11] M.V. Wolkin, J. Jorne, P.M. Fauchet, G. Allan, C. Delerue, Phys. Rev. Lett. 82 (1999) 197

[12] A. Stesmans, J. Appl. Phys. 92 (2002) 1317

[13] M.L. Green, T. Sorsch, L.C. Feldman, W.N. Lennard, E.P. Gusev, E. Garfunkel, H.C. Lu, T. Gustafsson, Appl. Phys. Lett. 71 (1997) 2978.

[14] M.-S. Yang, K.-S. Cho, J.-H. Jhe, S.-Y. Seo, J.H. Shin, K.J. Kim, D.W. Moon, Appl. Phys. Lett. 85 (2004) 3408. 